\title{
Matemática-em-uso na construção de objetos em movimento
}

\author{
Kellen Cardoso Barchinski, PPGEMAT/IME/UFRGS, kellencard09@gmail.com, \\ 0000-0001-5541-1163 \\ Márcia Rodrigues Notare, PPGEMAT/IME/UFRGS, marcia.notare@ufrgs.br, \\ 0000-0002-2897-8348
}

\begin{abstract}
Resumo: Esse artigo apresenta um estudo sobre o desenvolvimento do pensamento matemático em processo de construções de objetos em movimento. Para conduzir a pesquisa, foi elaborada uma oficina que aborda o estudo e a construção de objetos em movimento realizada com alunos do nono ano do Ensino Fundamental de uma escola pública municipal de Canoas, Rio Grande do Sul. A oficina propõe o uso do software GeoGebra para as construções virtuais e a utilização de material reciclável para as construções físicas dos mesmos objetos. O trabalho está ancorado nos estudos de Papert e inspira-se nas ideias propostas pela Cultura Maker e pelas metodologias ativas. Os resultados da pesquisa revelam que os estudantes desenvolveram diversos conhecimentos-matemáticos-em-uso, impulsionados pela motivação em construir instrumentos conhecidos das suas realidades, imersos em um ambiente de "faça o que é possível com as ferramentas que você tem".
\end{abstract}

Palavras-chave: tecnologias digitais, cultura maker, geometria dinâmica, objetos articulados.

\section{Mathematics-in-use in the construction of moving objects}

Abstract: This paper presents a study on the development of mathematical thinking in the process of construction moving objects. To conduct the research, a workshop was created that addresses the study and construction of moving objects carried out with students in the ninth grade of elementary school in a municipal public school of Canoas, Rio Grande do Sul. The workshop proposes the use of GeoGebra software for virtual constructions and the use of recyclable material for the physical constructions of the same objects. The work is based on Papert's studies and is inspired by the ideas proposed by the Maker Culture and by active methodologies. The survey results reveal that students developed several mathematical-knowledge-in-use, driven by the motivation to build instruments known to their realities, immersed in an environment of "do what is possible with the tools you have".

Keywords: digital technologies, maker culture, dynamic geometry, articulated objects.

\section{Introdução}

A pesquisa apresentada neste artigo foi realizada em um meio social de vulnerabilidade, da qual a primeira autora atua há quatro anos. Durante essa trajetória na escola, nota-se repetidamente que, mesmo vivendo em uma sociedade tecnológica, nem todos os alunos têm acesso a esses recursos. Nesta comunidade, raros são os alunos que possuem smartphone, raros são os alunos que possuem uma internet de qualidade, e aqueles que possuem dispositivo móvel fazem uso de aparelhos de qualidade precária que, frequentemente, são modelos mais antigos.

A escola e a aprendizagem, para muitos dos alunos desta comunidade, resumemse a um caderno e um lápis. Os recursos tecnológicos não fazem parte da realidade da escola como meio para aprender. Elaborar estratégias, relacionar matemática com o cotidiano, ou colocar a "mão na massa" em construções interessantes não fazem parte das 
rotinas da sala de aula neste contexto. Meier (2012) relata que os alunos possuem dificuldade em estabelecer conexões entre conteúdos matemáticos e suas interações com o mundo. Tais inquietações acabam tornando-se parte da rotina e das reflexões do professor. Como tornar nossas aulas momentos instigantes?

Dessa forma, a partir destas inquietações, foi realizada a seguinte pesquisa: Quais habilidades e conteúdos matemáticos emergem da construção de objetos em movimento físicos e virtuais?

Para a investigação, elaborou-se uma oficina, cujo objetivo foi trabalhar com a construção de mecanismos em movimento, físicos e virtuais, com estudantes do nono ano do Ensino Fundamental, que possuem em média 14 anos de idade. A partir das construções elaboradas pelos alunos ao longo da oficina, investigamos possibilidades de construção do conhecimento matemático, buscando por evidências de ação e compreensão de conceitos matemáticos empregados no processo de construção dos objetos em movimento. O artigo aqui apresentado, recorte da pesquisa mais ampla, aborda o uso de tecnologias digitais na escola, inspirado pelas ideias de metodologias ativas e pela Cultura Maker, trazendo a análise do processo de construção de um dos participantes da oficina.

\section{Revisitando as ideias de Seymour Papert}

Papert (1994) provoca-nos a refletir sobre como utilizar computadores nas aulas e manter o sistema de controle na escola. A questão hierárquica em uma escola, de que o professor ensina (portador de conhecimentos e comandos) a criança (que obedece às instruções), com o avanço tecnológico e a rapidez no acesso a informações, torna essa hierarquia falha, ou pelo menos questionável.

Nem sempre, nós professores, estamos preparados para o desafio que nos é imposto perante uma sala de aula repleta de computadores. Existe nessa situação um abismo sobre o que um computador, por exemplo, pode fazer e o que a sociedade (e, em especial, a escola) decidirá fazer com ele. Papert (1985) já mencionava que computadores podem ser os portadores de inúmeras ideias e sementes de mudança cultural e que tais mudanças podem acarretar quebra de barreiras entre a ciência e os seres humanos.

Um indivíduo em contato com o computador está interligado a uma forma de comunicação. O que queremos dizer é que quando operamos um computador precisamos nos comunicar com a linguagem da máquina. Papert (1985) descreve sobre programar computadores, e para ele programar significa comunicar-se com um computador numa linguagem que ambos possam "entender".

Atividades de programação (e acrescentamos aqui também atividades de construção), em que o estudante é o protagonista e o autor do produto que está sendo desenvolvido, podem refletir no desenvolvimento do que Papert (1994) chama de conhecimento-em-uso. Segundo o autor, o aprender-em-uso proporciona aos estudantes aprender de uma forma pessoal, e tal fato libera os professores para oferecer a seus alunos algo mais pessoal e mais gratificante para ambos. Papert (1994) ainda traz provocações sobre o estilo pessoal que cada professor tem de ensinar e sobre os currículos escolares. Será que todas as turmas de sétimo ano, por exemplo, devem aprender números inteiros no primeiro trimestre e devem saber operar, ordenar e classificar para estarem aptos a tirarem notas acima da média?

A criança, ao realizar atividades de programação ou construção no computador, está no controle da situação; a reação da máquina só irá ocorrer se a criança der as instruções ao computador. Nestas situações, a criança passa a desenvolver um raciocínio antecipado sobre a reação da máquina quando ela executar o programa ou testar suas construções, muitas vezes sustentado por conceitos matemáticos importantes que regulam 
esse processo, mesmo que nunca tenham sido "ensinados" à criança. Assim, para produzir algo com a máquina, é preciso pensar de forma antecipada sobre como alcançar o resultado desejado. A criança torna-se sua própria construtora de estruturas intelectuais e tal fato, cabe ressaltar, não significa dispensar a presença do professor no processo.

Papert (1988, p. 37) destaca a importância do aluno construtor:

\begin{abstract}
Em contraste quando a criança aprende a programar, o processo de aprendizagem é transformado. Em particular, o conhecimento adquirido para o propósito pessoal reconhecível. A criança faz alguma coisa com ele. O novo conhecimento é uma fonte de poder e é experienciado como tal a partir do momento que começa a se formar na mente da criança.
\end{abstract}

Papert (1988), em sua obra, trouxe à tona o debate sobre matofobia, que está relacionada aos tabus da aprendizagem e ao medo que a matemática pode causar nos estudantes. Em alguns casos, a matofobia acontece a partir do momento que certas definições não fazem mais sentido para o estudante. Quando algo deixa de fazer sentido, é comum que a criança perca o interesse em seguir adiante. A vontade de avançar muitas vezes é impulsionada pelo entendimento, afinal continuar investindo tempo, dedicação e concentração em algo que não compreendemos onde devemos chegar e nem mesmo os caminhos que devemos tomar parece não fazer sentido algum, em especial para as crianças.

Sobre a ideia de construções e alunos colocando a "mão na massa", Papert (1994) traz o conceito de bricolagem, que em poucas palavras diz: "use o que você tem, improvise e vire-se" (Papert, 1994, p.138). Esse conceito remete à ideia de pessoas realizando tarefas ou atividades nas quais não são especialistas. O fato é, use o que você tem para resolver seu problema, elabore estratégias, espere seu tempo, divida seu problema em partes e comece observando e identificando algo que você consiga resolver e que seja semelhante a algo que você já sabe. Em outras palavras, "divida e domine" para chegar ao resultado desejado, faça o que se pede com as ferramentas que você tem (e estamos falando aqui em ferramentais mentais) (Papert, 1994).

Se pensarmos no cotidiano, essa ideia nos remete a uma metodologia que permite nos aproximarmos de situações concretas. É como se tivéssemos algum equipamento quebrado em casa e quiséssemos, dentro de algumas horas, consertá-lo e utilizá-lo. Precisamos pensar sobre o que temos de ferramentas para o conserto, sobre a forma de utilizar tais ferramentas e de que maneira o equipamento será utilizado. Cabe lembrar que, para solucionar o problema do equipamento, não temos o manual de instruções e nem temos algum técnico disponível para tal. Nós é que daremos as coordenadas e tentaremos, de alguma forma, sanar o problema, com o conhecimento e as ferramentas que temos à disposição. E por que não podemos utilizar tais ideias na sala de aula? Por que não quebrar as barreiras e tabus de fórmulas prontas e receitas dadas?

\title{
3. A Cultura Maker
}

A ideia de cultura Maker tem origem datada na década de 70, a partir da implementação de computadores domiciliares e seu uso mais contínuo. A palavra Maker significa "fazer" e podemos associá-la à dinâmica do "faça você mesmo". O movimento Maker é um movimento crescente que envolve diferentes áreas de conhecimentos e pessoas, desde amadores, engenheiros e artistas. Mesmo a primeira iniciativa do movimento sendo datada em determinado momento, a atividade do fazer surge de antigas atividades, como a dos artesãos, marceneiros, costureiros e eletrônicos. Os recursos digitais, atualmente, permitem compartilhamento, divulgação, críticas e comentários sobre as construções realizadas. 
O fazer, no sentido atribuído pela cultura Maker, remete à ideia do indivíduo que executa as tarefas como um criador. Tais indivíduos são chamados Makers. Outro termo utilizado na literatura para as "pessoas que criam" são os fabricantes, que para Halverson e Sheridan (2014), estão associadas às identidades de cada indivíduo, que são capazes de inspirar diferentes abordagens teóricas e empíricas em um trabalho coletivo.

A cultura Maker inspirou esta pesquisa, dando a possibilidade de analisarmos e valorizarmos o cotidiano e a realidade dos estudantes, incentivando a construção ou aprimoramento de certos instrumentos, de acordo com as necessidades e vontades de cada um.

\section{Metodologias Ativas}

Segundo Moran (2018), desde que nascemos aprendemos com situações concretas, que aos poucos são ampliadas e generalizadas, indutivamente. Aos poucos também vamos aprendendo com teorias e ideias, que depois são testadas concretamente, pelo processo dedutivo. Assim como em outros processos, cada indivíduo aprende de uma forma.

\footnotetext{
As pesquisas atuais da neurociência comprovam que o processo de aprendizagem é único e diferente para cada ser humano, e que cada pessoa aprende o que é mais relevante e o que faz sentido para si, o que gera conexões cognitivas e emocionais. (Moran, 2018, p.2)
}

As metodologias ativas e as tecnologias digitais estão associadas ao dinamismo e rapidez com que as informações são acessadas. A ideia de compartilhamento é ressaltada, visto que a colaboração é aumentada com o uso de conectividade. Salas de aula não ficam mais baseadas apenas a atos e sim ganham visão geral por meio de murais online e redes sociais de comunicação e não somente àqueles que se faziam presentes pessoalmente nas aulas. Agora, temos a opção de expor nossas ideias e projetos para um grande número de pessoas por meio do compartilhamento de informações pela internet. Tal cenário para os jovens é rotineiro, afinal, todas as vezes que alguma informação é publicada em redes sociais ou em grupos de aplicativos, o indivíduo já tem em mente que aquele conteúdo vai chegar a diversas pessoas e que tais pessoas podem tecer comentários sobre a publicação.

Dentro dessa perspectiva, temos o modelo de sala de aula invertida, que tem como proposta principal a ideia do professor dando suporte e referências aos alunos, e a pesquisa sobre informações básicas sobre o tópico de estudo fica a cargo do aluno, nas mais diversas oportunidades informativas de que dispõe. Conforme o assunto vai avançando, o professor vai adentrando nos conceitos mais aprofundados e criando atividades de acordo com cada desenvolvimento apresentado. Cada aluno irá acessar o conteúdo de acordo com o nível que atingir, assim gradativamente. O trabalho é colaborativo, dadas as trocas e interações que estudantes e professor fazem durante $o$ processo.

\section{Procedimentos Metodológicos}

Essa pesquisa, de cunho qualitativo, busca investigar habilidades e conteúdos matemáticos que emergem da construção de objetos físicos e virtuais em movimento. Dessa forma, elaborou-se a oficina "Construindo objetos em movimento" que propõe o trabalho inspirado em espaços Maker, nos quais os alunos são protagonistas no processo de construção de objetos em movimento físicos a partir de materiais reciclados, e de objetos virtuais no ambiente de matemática dinâmica GeoGebra. A pesquisa conta com o envolvimento de estudantes do nono ano do Ensino Fundamental de uma escola da rede pública municipal do município de Canoas, Rio Grande do Sul. 
A investigação consiste em uma pesquisa qualitativa, pois foi baseada em dados empíricos de observações. Para a produção de dados, utilizamos o registro de imagens, vídeos e os cadernos de campo dos alunos e da pesquisadora, a partir do acompanhamento e observação do trabalho dos participantes nos encontros da oficina. A análise de dados foi conduzida pela observação detalhada das ações e produções de quatro estudantes que participaram da oficina proposta.

Para a organização da oficina, foi desenvolvido um GeoGebraBook, intitulado "Articulações e Movimentos" (https://www.geogebra.org/m/yvw9cjbs). A Figura 1 ilustra uma das telas do livro digital.

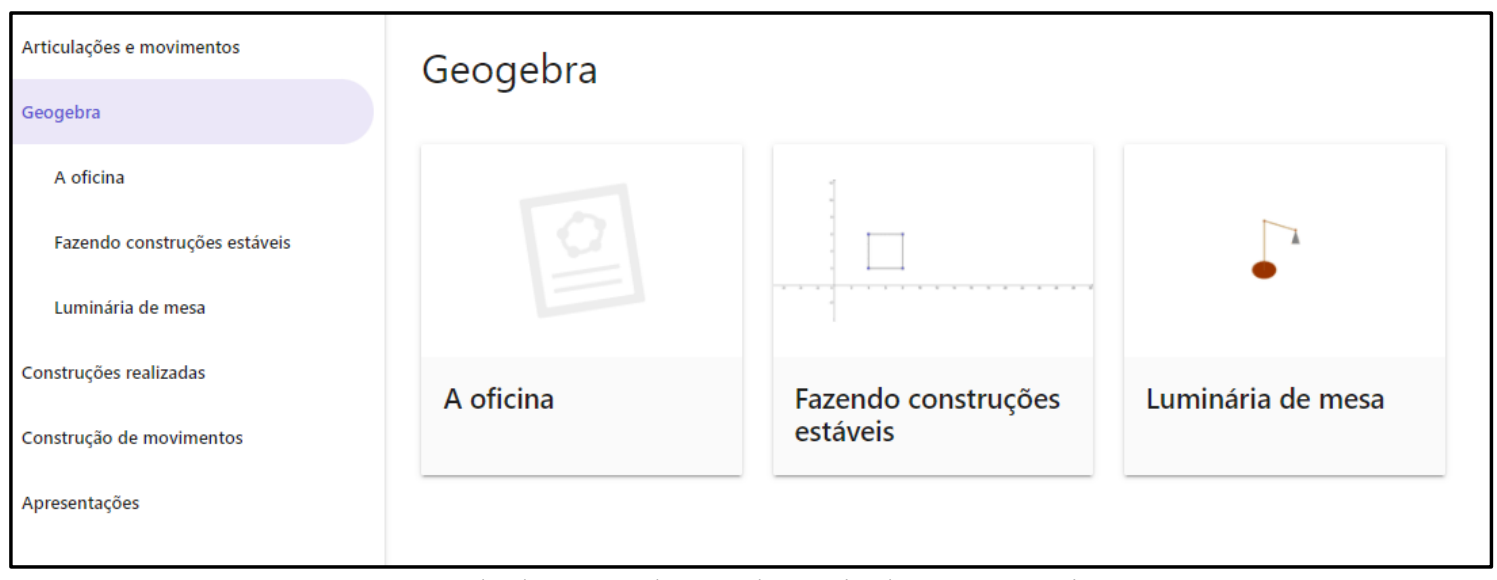

Figura 1. Tela do GeoGebraBook "Articulações e Movimentos"

Fonte: https://www.geogebra.org/m/yvw9cjbs

Apresentamos na seção a seguir um recorte da análise dos dados produzidos.

\section{Análise dos dados: investigando a matemática-em-uso}

Trazemos para análise uma das produções de um estudante, o qual denominaremos de E1. A atividade proposta era: construir um objeto com movimento que possa ser útil no seu dia-a-dia ou no cotidiano da sua comunidade. O aluno E1 decidiu construir um "fechador de pastel" (semelhante ao ilustrado na Figura 2), impulsionado pelas atividades realizadas por sua mãe, que prepara pastéis para vender.

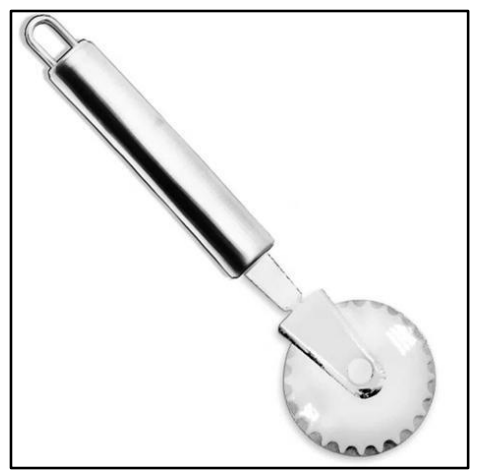

Figura 2. Fechador de pastel que inspirou a produção do aluno Fonte: http://google.com

O aluno iniciou sua construção pela base do fechador, construindo a parte de formato circular, que possui um movimento de rotação. No extrato a seguir, trazemos o registro de E1 sobre o processo de construção desta etapa. 
E1: Para fazer o fechador de pastel primeiramente fiz um círculo e dentro desse círculo, com a função polígono rígido fui tentando fazer mini triângulos, porém estava ficando muito torto e apaguei. Então eu me lembrei que era possível mudar a malha, então coloquei uma malha circular, então o círculo ficou simétrico para fazer os triângulos que seriam os dentes que iam fechar o pastel.

Identificamos no registro de E1 a ideia de bricolagem, que em poucas palavras sugere: "use o que você tem, improvise e vire-se" (Papert, 1994, p.138). O "bricolador", no sentido abordado por Papert (1994), remete à ideia de pessoas realizando tarefas nas quais não são especialistas. Papert defende que se pode usar o que se tem para dar conta do desafio, estabelecer estratégias, dar-se tempo, dividir o problema maior em partes, observar e analisar para resolver etapas que possam ser semelhantes a algo já realizado, resgatando no repertório de ferramentais mentais, aquelas que podem ser úteis para obter sucesso na tarefa ou em parte dela. E este foi o comportamento observado nas ações de E1: ele tentou construir "mini triângulos", mas não gostou do resultado (pois estavam "muito tortos"). Então, vasculhando em sua "caixa de ferramentas mentais" (e também nas ferramentas do GeoGebra), lembrou da "malha circular", que permitiu a construção do círculo e dos triângulos da forma como desejava. Percebemos que E1, conforme defende Papert (1994), "dividiu e dominou" para chegar ao resultado desejado.

Destacamos que, em nenhum momento do encontro, foi sugerido a E1 a troca de malha. O aluno, por meio de suas ações e motivado pelo seu objetivo de construção, tomou a decisão de trocar e malha. A Figura 3 ilustra esta etapa de construção de E1.

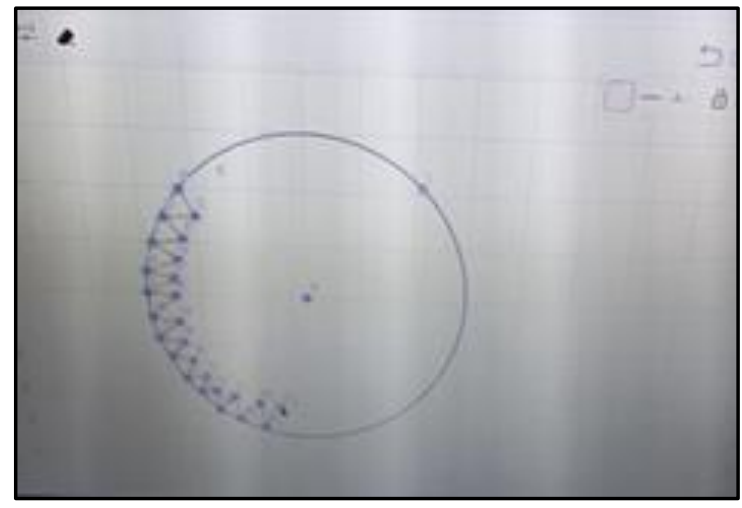

Figura 3. Construção do fechador de pastel - Tentativa 1 Fonte: Dados da Pesquisa

Ao manipular sua construção, arrastando os pontos com liberdade de movimento, E1 ficou incomodado com a instabilidade e com a deformação que ocorria com seu fechador de pastel virtual. Papert (1988) salienta que, ao se programar uma máquina (e neste caso, ao se realizar uma construção geométrica no GeoGebra) sem que haja receitas prontas para os seus comandos, inspirados em tutorias que dizem como o aluno deve proceder, normalmente nas primeiras tentativas não conseguimos obter o êxito esperado. Nestes casos, quando não chegamos ao resultado desejado, nossas estratégias devem ser retomadas, analisadas e, possivelmente, alteradas. E uma das formas de fazer isso é analisar a construção e procurar a "chave" que provocou o resultado inesperado. Episódios como este, quando ocorrem em aulas com lápis e papel, normalmente acabam por apagar com a borracha todo o desenvolvimento, sem procurar analisar o que já foi produzido. Pouco se analisa o ponto chave que provocou o erro. Pouco se pergunta "Onde posso melhorar minha estratégia para chegar onde quero?". Para Moran (2008) as metodologias ativas dão ênfase ao papel do protagonista do aluno, ao seu envolvimento RENOTE 
direto, participativo e reflexivo em todas as etapas do processo, experimentando, desenhando e criando e buscando soluções quando os obstáculos aparecem.

Assim, E1 não desistiu de aprimorar sua construção, dando continuidade ao processo. A seguir, seguem os registros de E1 sobre seu processo de construção, revelando as tentativas, as falhas e as superações.

E1: Depois fiz um círculo no meio e botei 2 pontos no círculo e puxei um segmento para frente, e o outro ponto também fiz a mesma coisa, e liguei tudo com o meio do círculo, formando o bastão do fechador de pastel e movimentei tudo. E desmontou tudo. Então, liguei os dentes no círculo com segmento fixo ab e depois ocultei ele, em seguida fiz outras linhas com segmentos fixo, então consegui movimentar tudo.

Após as mudanças de estratégias (e das ferramentas utilizadas) em sua construção, E1 construiu o seu fechador de pastel como desejava, conforme mostra a Figura 4.

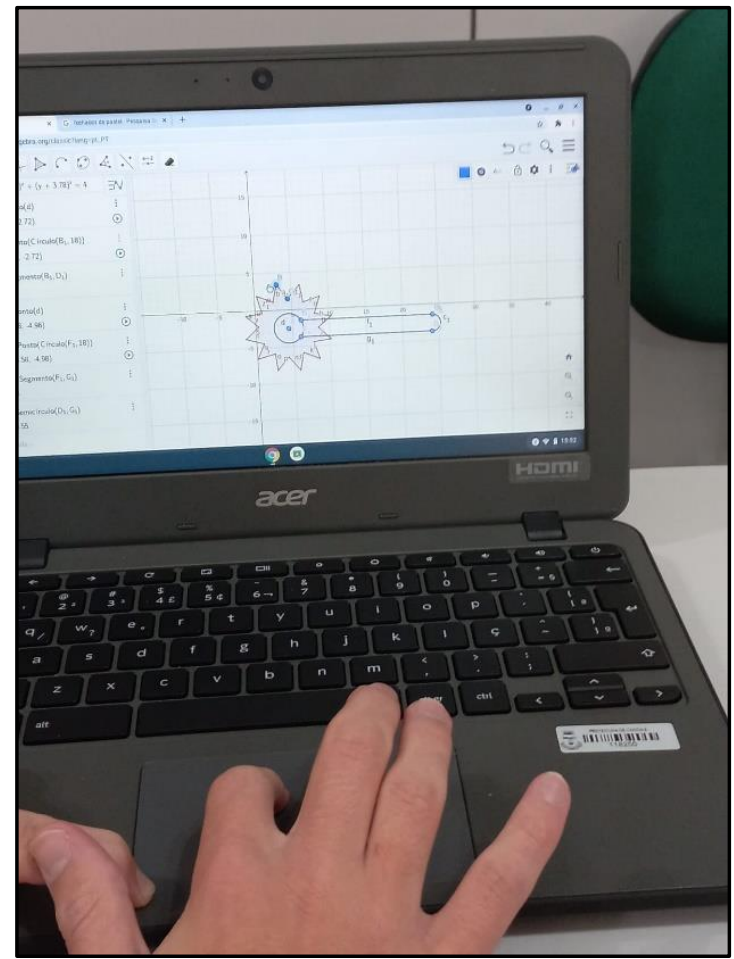

Figura 4. Construção do fechador de pastel - Versão final Fonte: Dados da Pesquisa

E sobre os conceitos matemáticos, o que E1 aprendeu? De imediato, poderíamos elencar a utilização dos objetos geométricos presentes em sua construção: noção de círculo e raio, mas também de círculos concêntricos, que permitiram o aspecto visual desejado; noção de congruência de segmentos de retas, para garantir que todos os dentes do fechador de pastéis tivessem o mesmo tamanho; noção do movimento de rotação, implícito no instrumento escolhido por ele para construção. Além disso, E1 foi capaz de descobrir e utilizar a malha de coordenadas polares, mesmo sem estudar as formalizações deste conceito, revelando um processo de aprender-em-uso, apontado por Papert (1988). Notamos também, o aprimoramento na linguagem geométrica de E1, provavelmente impulsionado pela utilização dos menus do software, referindo-se aos objetos geométricos corretamente, conforme podemos observar em suas falas.

Destacamos que, na oficina "Articulações e Movimentos", o processo de aprendizagem dos estudantes e, em especial de E1, foi transformado. O conhecimento adquirido foi impulsionado pela vontade de criar um instrumento da sua realidade, 
caracterizando-se como um propósito pessoal de E1. O estudante E1 reconhece que o objeto é real e útil para sua mãe e isto o estimulou a construir também na versão virtual. O novo conhecimento construído por E1, mesmo que sem as formalizações de uma sala de aula convencional, torna-se uma fonte de poder criativo. Conforme defende o movimento da cultura Maker, a era do "fazer" toma o espaço da era da "memorização", possibilitando um aprender-em-uso pessoal e descolado do currículo escolar.

Nas palavras de Papert (1985),

Minha suposição é que o computador pode concretizar (e personalizar) o formal. Sob este prisma, o computador não é somente mais um instrumento educacional poderoso. Ele é o único a nos permitir os meios para abortar o que Piaget e muitos outros identificam com o obstáculo que deve ser transposto para a passagem do pensamento infantil para o pensamento adulto. (Papert, 1985 p. 37)

Dando continuidade ao trabalho na oficina, E1 passou para a construção do fechador de pastel físico, utilizando os materiais recicláveis disponíveis na escola. Para construir seu fechador de pastel, E1 selecionou pedaços de papelão e utilizou um compasso para traçar o círculo no papelão e recortar. Temos aqui a utilização de ferramentas geométricas físicas, que exigem habilidades manuais, mas também conhecimentos-matemáticos-em-uso como o raio que vai determinar o tamanho do instrumento construído. Para construir as garrinhas que fecham o pastel no círculo, E1 pensou em como poderia construir triângulos, lembrando de sua construção no GeoGebra. Assim, E1 buscou na caixa de materiais recicláveis uma tampinha de garrafa para analisar como eram construídas suas garrinhas. Observando as marcações na tampinha, E1 decidiu contá-las para utilizar essa ideia na sua construção. Assim, E1 dividiu seu círculo em tamanhos iguais de marcações para traçar os segmentos que formariam os triângulos, ou seja, as garrinhas do fechador de pastel. Halverson e Sheridan (2014) afirmam que aprender por meio do fazer ultrapassa a linha entre aprendizado formal e informal, provocando-nos a pensar de maneira ampla sobre onde e quando a aprendizagem acontece. A Figura 5 mostra E1 engajado em sua construção.

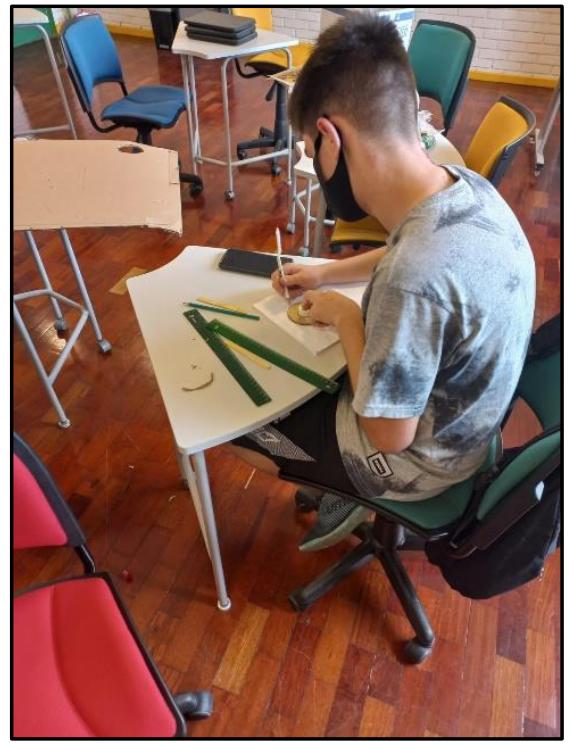

Figura 5. E1 construindo o fechador de pastel físico

Fonte: Dados da pesquisa

Após fazer as marcações, E1 recortou a parte circular e dentada de seu instrumento. Em seguida, pensando no movimento de rotação do objeto, E1 perfurou o centro do círculo e recortou duas hastes. Finalmente, para finalizar sua construção, E1 utilizou um palito que transpassou as hastes e o círculo e possibilitou o movimento 
funcional de rotação de um fechador de pastéis, como mostra a Figura 6. Identificamos evidências da noção de centro de rotação de E1. A utilização do palito também realça a compreensão sobre o movimento, pois, caso o estudante colasse as partes do instrumento, o movimento de rotação não seria possível.

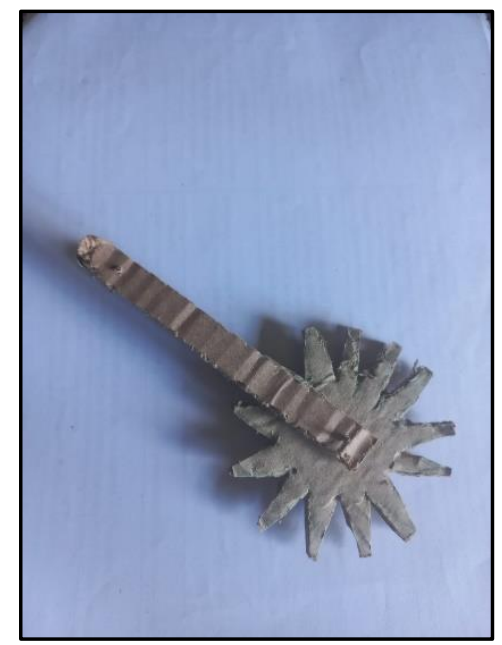

Figura 6. Fechador de pastel físico - Versão Final Fonte: Dados da pesquisa

A cultura do "siga o modelo", nessa perspectiva, acaba perdendo força para dar espaço à autonomia de ação e de construção do indivíduo. Fórmulas prontas, atividades de copiar e colar, pintar o desenho pronto já não fazem mais sentido nesta perspectiva. Muitas vezes a curiosidade e a criatividade só são despertadas por assuntos e temas de interesse dos indivíduos e se dermos oportunidades para que elas aflorem.

\section{Considerações Finais}

As tecnologias digitais propiciam a reconfiguração da prática pedagógica, além da abertura e da plasticidade do currículo escolar. Vimos, com a experiência analisada na oficina "Articulações e Movimentos", que conhecimentos matemáticos foram utilizados, mesmo que o professor nunca tenha "ensinado" estes conceitos aos participantes em nenhum momento. $\mathrm{O}$ aluno aprende-em-uso sobre conceitos matemáticos, que emergem da necessidade de construir seus projetos.

$\mathrm{Na}$ oficina realizada, que teve duração de seis encontros, os estudantes que se envolveram nas construções de objetos em movimento (a saber, braços de luminária de mesa, escavadeira, porta pantográfica, perna mecânica entre outros) não realizaram construções impecáveis, mas realizaram construções possíveis, dentro das possibilidades que suas "caixas de ferramentas matemáticas" permitiram. Tornaram-se bricoladores mirins, colocaram a "mão na massa" e agregaram novas ferramentas em seu repertório, adquirindo novos conhecimentos que poderão ser formalizados em experiências posteriores.

\section{Referências}

BLIKSTEIN, P. Digital Fabrication and 'Making' in Education: The Democratization of Invention. In: J. Walter-Herrmann \& C. Büching (Org.). FabLabs: Of Machines, Makers and Inventors. Bielefeld: Transcript Publishers, 2013. p. 203-221.

BOGDAN, R. C.; BIKLEN, S. K. Investigação qualitativa em educação: uma introdução à teoria e aos métodos. Porto: Porte Editora, 1994. 
BRASIL. Ministério da Educação. Base Nacional Comum Curricular. Brasília, 2018.

HALVERSON, e. r.; SHERIDAN, K. M. The Maker Moviment in Education. Harvad Educational Review, 2014.

MEIER, M. Modelagem geométrica e o desenvolvimento do pensamento matemático no Ensino Fundamental. Porto Alegre: UFRGS, 2012, 146p. Dissertação de Mestrado.

MORAN, J. BACICH, L. Metodologias ativas para uma aprendizagem mais profunda. Porto Alegre. Penso, 2018.

PAPERT, S. A máquina das crianças. Repensando a escola na era da informática. Porto Alegre: Artes Médicas, 1994.

PAPERT, S. Logo: computadores e educação. São Paulo. Editora Brasiliense, 1985.

UNESCO. Educação. Um tesouro a descobrir. Relatório para a UNESCO da Comissão Internacional sobre Educação para o século XXI. 2010. 